\title{
The imprint of thermally induced devolatilization phenomena on radon signal: implications for the geochemical survey in volcanic areas
}

\author{
Silvio Mollo, ${ }^{1}$ Paola Tuccimei, ${ }^{2}$ Gianfranco Galli, ${ }^{3}$ Gianluca Iezzi ${ }^{4}$ \\ and Piergiorgio Scarlato ${ }^{3}$ \\ ${ }^{1}$ Dipartimento di Scienze della Terra, Sapienza-Università di Roma, P.le Aldo Moro 5, I-00185 Roma, Italy. E-mail: silvio.mollo@uniroma1.it \\ ${ }^{2}$ Dipartimento di Scienze, Università “Roma Tre”, Largo S. L. Murialdo 1, I-00146 Roma, Italy \\ ${ }^{3}$ Istituto Nazionale di Geofisica e Vulcanologia, Via di Vigna Murata 60, I-00143 Roma, Italy \\ ${ }^{4}$ Dipartimento di Ingegneria and Geologia, Università G. d'Annunzio, Via dei Vestini 30, I-66013 Chieti, Italy
}

Accepted 2017 July 27. Received 2017 July 26; in original form 2016 November 28

\begin{abstract}
S U M MAR Y
Thermal gradients due to magma dynamics in active volcanic areas may affect the emanating power of the substrate and the background level of radon signal. This is particularly effective in subvolcanic substrates where intense hydrothermal alteration and/or weathering processes generally form hydrous minerals, such as zeolites able to store and release great amounts of $\mathrm{H}_{2} \mathrm{O}$ (up to $\sim 25 \mathrm{wt} . \%$ ) at relative low temperatures. To better understand the role played by thermally induced devolatilization reactions on the radon signal, a new experimental setup has been developed for measuring in real time the radon emission from a zeolitized volcanic tuff. Progressive dehydration phenomena with increasing temperature produce radon emissions two orders of magnitude higher than those measured during rock deformation, microfracturing and failure. In this framework, mineral devolatilization reactions can contribute significantly to produce radon emissions spatially heterogeneous and non-stationary in time, resulting in a transient state dictated by temperature gradients and the carrier effects of subsurface gases. Results from these experiments can be extrapolated to the temporal and spatial scales of magmatic processes, where the ascent of small magma batches from depth causes volatile release due to dehydration phenomena that increase the radon signal from the degassing host rock material.
\end{abstract}

Key words: Heat flow; Hydrothermal systems; Magma chamber processes; Volcanic gases; Volcanic hazards and risks.

\section{INTRODUCTION}

Radon is one of the most monitored gases on Earth as precursor of earthquakes (Hauksson 1981; Roeloffs 1988; Toutain \& Baubron 1999; Hartmann \& Levy 2005; Cicerone et al. 2009; Woith 2015; Martinelli \& Dadomo 2017). In this framework, Woith (2015) reviewed more than 100 of studies dealing with fluid-related radon anomalies measured before earthquakes, concluding that radon anomalies of non-tectonic origin can be very similar to those of seismotectonic origin. As a consequence, only a fraction of observed radon precursors are physically related to crust deformations and earthquake events. More recently, Martinelli \& Dadomo (2017) reappraised the possible favourable and unfavourable geophysical conditions to generate fluid-related earthquake precursory signals, evidencing that they occur in particular areas of the world where strong crustal deformative processes, high heat flow values and shallow seismicity are recognized.
One of the possible mechanisms to explain anomalous increase of radon signal in soil and groundwater is rock fracturing at depth under variable tectonic regimes (Thomas 1988). In this context, a number of experimental studies were conducted to decipher the relationship between radon emission and rock deformation (Holub \& Brady 1981; Tuccimei et al. 2010, 2015; Mollo et al. 2011; Scarlato et al. 2013; Nicolas et al. 2014; Koike et al. 2015; Zhang et al. 2016). Nonetheless, the marked increase of radon emission in a monitored area is not unequivocally related to rupture episodes in the Earth's crust (Kerr 1978; King 1981; Tsunogai \& Wakita 1995; Steinitz et al. 2003). There are many physicochemical phenomena that develop between radon escaping from a volcanic rock in the ground and the radon measurement at ground surface. For example, thermal gradients at subvolcanic conditions (Scarlato et al. 2013) and in geothermal areas (Finizola et al. 2010; Ricci et al. 2015) may affect the emanating power of the substrate and the background level of geochemical signals. Most of the monitored and active 
volcanoes around the world are characterized by continuous injections of magma that stall at very shallow levels or feed complex dyke networks, even at a few metres from the ground surface. The conductive heat flow may produce thermal gradients in the host rocks from $1100{ }^{\circ} \mathrm{C}$ at the contact to $200{ }^{\circ} \mathrm{C}$ at a distance of thousands of metres, incorporating several cubic kilometres of the substrate (Bonaccorso et al. 2010; Mollo et al. 2012; Heap et al. 2013). The radon emission from the warm host rock is expected to be controlled by the dependency of the gas diffusion coefficient on temperature (Beckman \& Balek 2002; Voltaggio et al. 2006). However, poorly consolidated and highly porous volcanic rocks (i.e. pyroclastic flow deposits) are accompanied by intense alteration processes due to hydrothermal phenomena (Merle et al. 2010), but most frequently chemical weathering caused by temperature changes and rainfalls over geological times (Passaglia et al. 1990). These processes lead to the formation of amorphous glass, silica polymorph, clay and zeolite. The cages and channels within the zeolite framework have the capability of adsorbing or rejecting $\mathrm{H}_{2} \mathrm{O}$ molecules via repeated hydration and dehydration reactions due to temperature changes. Although natural zeolite minerals show low radon adsorption capability (Bikit et al. 2015), the abundant $\mathrm{H}_{2} \mathrm{O}$ release (up to $\sim 25 \mathrm{wt} . \%$ ) under subvolcanic temperatures may act as a carrier for radon by electrical forces (Shuleikin 2015) and advective gas transport (Baskaran 2016), especially in geomaterials with a high macroporosity (Etiope \& Martinelli 2002). In contrast, the excess of $\mathrm{H}_{2} \mathrm{O}$ in porous rocks may produce isolation phenomena hampering radon transport due to adsorption of $\mathrm{H}_{2} \mathrm{O}$ molecules on the porous surfaces and subsequent saturation of the medium via $\mathrm{H}_{2} \mathrm{O}$ condensation mechanisms (Fernandez-Cortes et al. 2013).

During long intereruptive periods of hundreds to thousands of years, a volcano passes through different stages of activity in which a variety of meteoric, hydrothermal, metamorphic and igneous processes are recognized as sources of $\mathrm{H}_{2} \mathrm{O}$ vapour and other degassing phenomena (Oppenheimer 2003). Generally, due to its low solubility in ascending magmas, $\mathrm{CO}_{2}$ is the most important carrier gas for radon, being also used to map subvolcanic faults and fractures (Giammanco et al. 2007). However, increasing radon emissions are not necessary related to carrier gases of magmatic origin and, consequently, a decoupled spatial and temporal behaviour can be observed during eruptive and seismic activities (Heiligmann et al. 1997). Moreover, in volcanic areas, the radon signal may be spatially heterogeneous and non-stationary in time (Kotsarenko et al. 2016; Neri et al. 2016). Understanding the different gas sources is important to correctly interpret the radon behaviour and its relationship to degassing processes. To investigate this relationship, a novel experimental setup has been designed for measuring in real time the radon emission from a zeolitized volcanic tuff undergoing dehydration and rehydration cycles. Results from these experiments evidence that the behaviour of radon in volcanic settings is more complex than so far assumed. In addition to carrier effects due to magmatic gas fluxes, thermally induced devolatilization reactions of $\mathrm{H}_{2} \mathrm{O}$-bearing minerals in rocks exposed to subvolcanic temperatures may substantially increase or decrease the radon emission.

\section{METHODS}

\subsection{Starting material}

The starting material used for the experiments is the so-called 'Tufo Rosso a Scorie Nere' (hereafter named TRSN), a tuff from an ignimbrite deposit of the Vico volcanic apparatus (Latium, Italy;
Palladino et al. 2014), extending over an area of $1200 \mathrm{~km}^{2}$. TRSN is a well-characterized product (Passaglia et al. 1990; Giampaolo et al. 2008; Tuccimei et al. 2010, 2015; Mollo et al. 2011; Scarlato et al. 2013; see also mineral textures and compositions reported in the Supporting Information) consisting of phenocrysts of magmatic origin (clinopyroxene $+\mathrm{K}$-feldspar + plagioclase), clay (ilmenite + kaolinite) and zeolite (chabazite) minerals due to hydrothermal alteration, a fine cineritic matrix (residual glass), and millimetre- to centimetre-sized vesicles ( $\sim 47 \%$ of total porosity). TRSN has a high radium activity $\left({ }^{226} \mathrm{Ra}=254 \mathrm{~Bq} \mathrm{~kg}^{-1}\right)$ and high uranium $(21.2 \mathrm{ppm})$ and thorium (52.3 ppm) contents, translating to natural ${ }^{222} \mathrm{Rn}$ and ${ }^{220} \mathrm{Rn}$ exhalation rates of 7.9 and $314 \mathrm{~Bq} \mathrm{~kg}{ }^{-1} \mathrm{~h}^{-1}$, respectively (e.g. Tuccimei et al. 2010). The original ${ }^{220} \mathrm{Rn}$ activity of TRSN measured at $25^{\circ} \mathrm{C}$ corresponds to $990 \pm 30 \mathrm{~Bq} \mathrm{~m}^{-3}$, as reported in Tuccimei et al. (2015).

\subsection{Experiments}

For the purpose of this study, two cylindrical rock samples (i.e. TRSN1 and TRSN2; $60 \mathrm{~mm}$ in diameter and $140 \mathrm{~mm}$ in length) were cored from the same block and then used for the following radon experiments:

(1) Dehydration EXP1. TRSN1 was heated in eight steps of 100, $200,300,400,500,600,700$ and $800{ }^{\circ} \mathrm{C}$ and then cooled in seven steps of $700,600,500,400,300,200$ and $100{ }^{\circ} \mathrm{C}$,

(2) Dehydration EXP2. TRSN2 was heated in four steps of 100 , 170,230 and $450{ }^{\circ} \mathrm{C}$.

(3) Dehydration/dehydration EXP3. TRSN2 was rehydrated and then reheated at the same conditions of EXP2 by including further step at $800{ }^{\circ} \mathrm{C}$.

(4) Dehydration/dehydration EXP4. TRSN2 was rehydrated and then reheated at the same conditions of EXP3.

The rehydration of TRSN2 was obtained by immersion in deionized water for $3 \mathrm{~min}$ and then exposure to ambient conditions over $3 \mathrm{~d}$ (Shim et al. 1999). The time duration of heating/cooling ramps and the acquisition time of a single ${ }^{220} \mathrm{Rn}$ measurement cycle were $30 \mathrm{~min}$. To ensure (1) thermal homogenization of the sample, (2) complete release of volatile at each specific experimental temperature and (3) a low analytical uncertainty, four cycles were acquired for each radon measurement over a total time duration of $120 \mathrm{~min}$ (Table 1). Therefore, ${ }^{220} \mathrm{Rn}$ activity discussed in this study is the average of four measurement cycles. The only exception are the modelling data reported in Table 2 that come from a replicated experiment where TRSN was heated in seven steps of 100, 200, 300, 400, 500, 600 and $700{ }^{\circ} \mathrm{C}$ using 10 acquisition cycles for a longer time duration of $300 \mathrm{~min}$. This allows us to model the variation of radon signal over temporal and spatial scales comparable to those observed in subvolcanic environments where heat flow is released from the hot magma toward the cold host rock (see discussion below). The influence of other parameters on radon emission (i.e. the air relative humidity and detection temperature in the closedloop configuration) has been already discussed in previous studies (Tuccimei et al. 2009, 2011; De Simone et al. 2016).

\subsection{Radon correction method}

Radon gas emitted from rock samples was delivered to a continuous Radon Monitor (RAD7, Durridge Company), equipped with a solid-state silicon alpha detector, and counted before being released from the outlet of the instrument. ${ }^{220} \mathrm{Rn}$, rather than ${ }^{222} \mathrm{Rn}$, 
Table 1. Radon emissions measured during the experiments as a function of temperature changes.

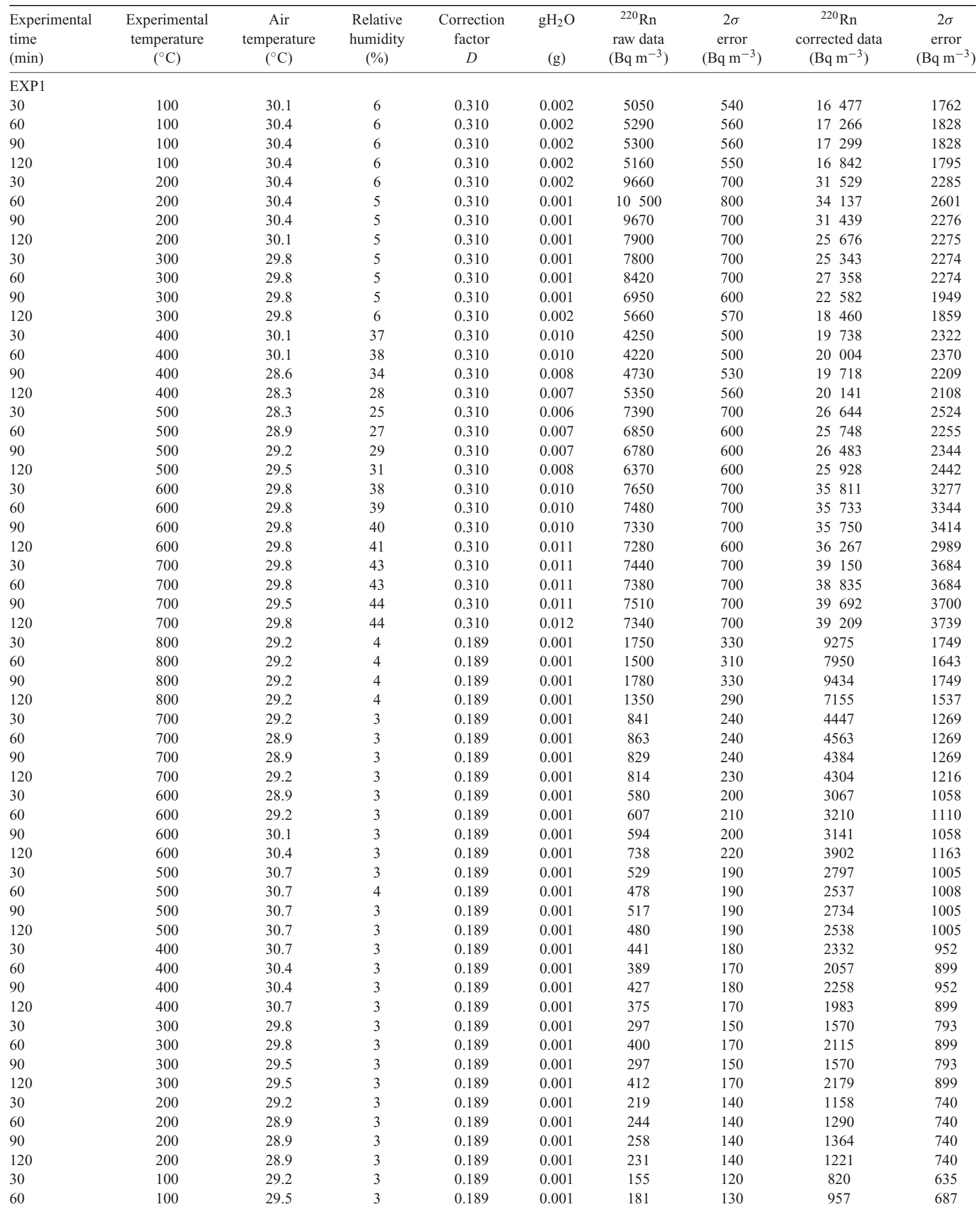


Table 1 - continued

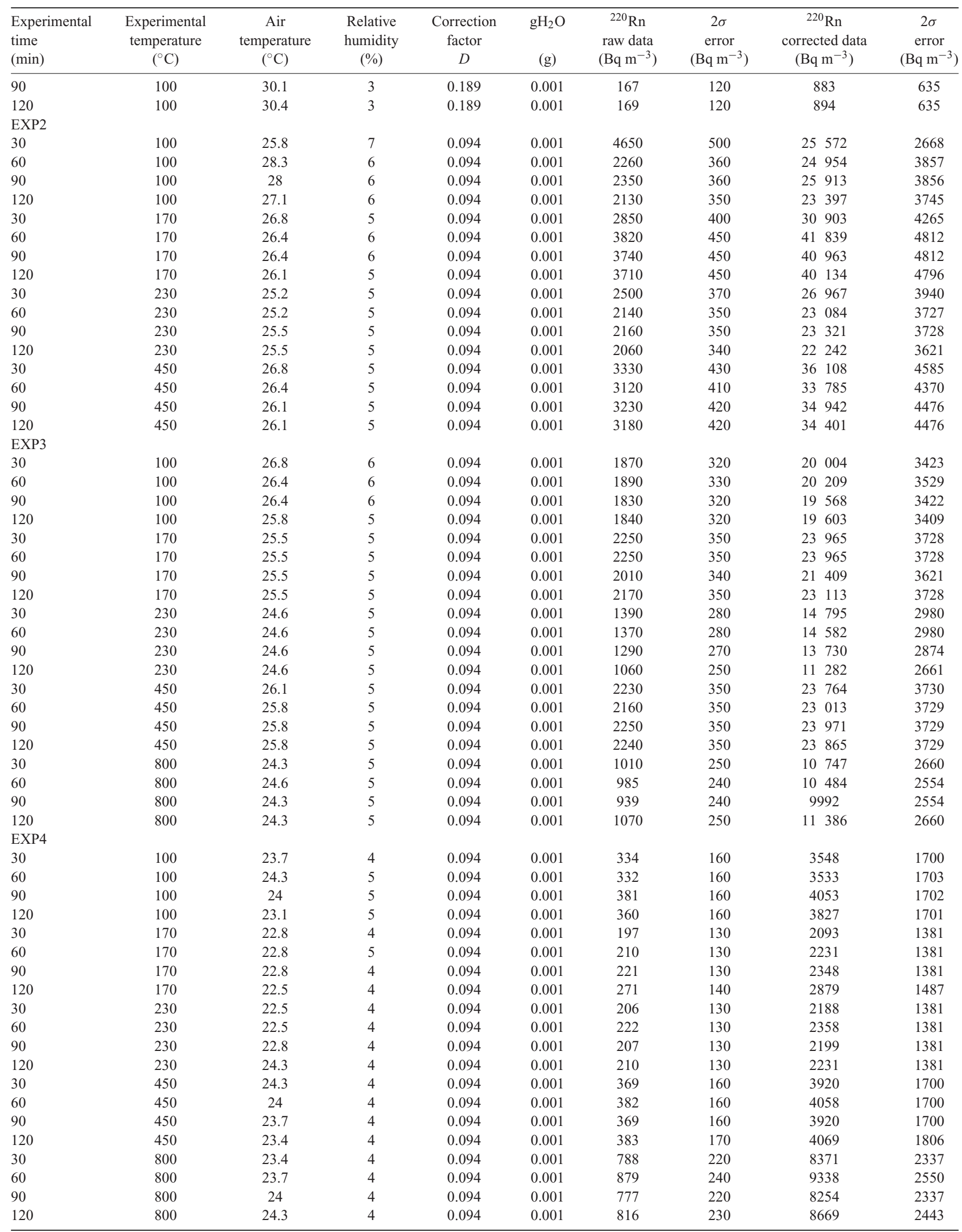


Table 2. Modelling data measured from a replicated experiment where TRSN was heated in seven steps of $100,200,300,400,500,600$ and $700{ }^{\circ} \mathrm{C}$ using 10 acquisition cycles for a longer time duration of $300 \mathrm{~min}$.

\begin{tabular}{|c|c|c|c|c|c|c|c|c|c|}
\hline $\begin{array}{l}\text { Experimental } \\
\text { time } \\
(\mathrm{min})\end{array}$ & $\begin{array}{c}\text { Experimental } \\
\text { temperature } \\
\left({ }^{\circ} \mathrm{C}\right)\end{array}$ & $\begin{array}{c}\text { Air } \\
\text { temperature } \\
\left({ }^{\circ} \mathrm{C}\right)\end{array}$ & $\begin{array}{c}\text { Relative } \\
\text { humidity } \\
(\%)\end{array}$ & $\begin{array}{l}\text { Correction } \\
\text { factor } \\
D\end{array}$ & $\begin{array}{c}\mathrm{gH}_{2} \mathrm{O} \\
(\mathrm{g})\end{array}$ & $\begin{array}{c}{ }^{220} \mathrm{Rn} \\
\text { raw data } \\
\left(\mathrm{Bq} \mathrm{m}^{-3}\right)\end{array}$ & $\begin{array}{c}2 \sigma \\
\text { error } \\
\left(\mathrm{Bq} \mathrm{m}^{-3}\right)\end{array}$ & $\begin{array}{c}{ }^{220} \mathrm{Rn} \\
\text { corrected data } \\
\left(\mathrm{Bq} \mathrm{m}{ }^{-3}\right)\end{array}$ & $\begin{array}{c}2 \sigma \\
\text { error } \\
\left(\mathrm{Bq} \mathrm{m}^{-3}\right)\end{array}$ \\
\hline 150 & 100 & 29.8 & 6 & 0.310 & 0.001 & 5000 & 510 & 16307 & 1663 \\
\hline 210 & 100 & 30.4 & 6 & 0.310 & 0.001 & 5190 & 560 & 16940 & 1828 \\
\hline 240 & 100 & 30.4 & 6 & 0.310 & 0.001 & 5100 & 560 & 16646 & 1828 \\
\hline 270 & 100 & 30.4 & 6 & 0.310 & 0.001 & 4910 & 530 & 16026 & 1730 \\
\hline 360 & 100 & 30.4 & 6 & 0.310 & 0.001 & 4900 & 520 & 15993 & 1697 \\
\hline 390 & 100 & 30.4 & 6 & 0.310 & 0.001 & 5050 & 540 & 16483 & 1763 \\
\hline 420 & 100 & 30.4 & 6 & 0.310 & 0.001 & 4940 & 520 & 16124 & 1697 \\
\hline 450 & 200 & 30.4 & 6 & 0.310 & 0.001 & 9460 & 700 & 30877 & 2285 \\
\hline 480 & 200 & 30.4 & 5 & 0.310 & 0.001 & 9250 & 800 & $\begin{array}{ll}30 & 073\end{array}$ & 2601 \\
\hline 510 & 200 & 30.4 & 5 & 0.310 & 0.001 & 9370 & 700 & 30463 & 2276 \\
\hline 660 & 200 & 30.1 & 5 & 0.310 & 0.001 & 9381 & 530 & 30490 & 1723 \\
\hline 690 & 200 & 30.1 & 5 & 0.310 & 0.001 & 9260 & 500 & 30096 & 1625 \\
\hline 720 & 200 & 30.1 & 5 & 0.310 & 0.001 & 9470 & 510 & 30779 & 1658 \\
\hline 750 & 300 & 29.8 & 5 & 0.310 & 0.001 & 7200 & 700 & 23394 & 2274 \\
\hline 780 & 300 & 29.8 & 5 & 0.310 & 0.001 & 7320 & 700 & 23784 & 2274 \\
\hline 810 & 300 & 29.8 & 5 & 0.310 & 0.001 & 7250 & 600 & 23556 & 1949 \\
\hline 840 & 300 & 29.8 & 6 & 0.310 & 0.001 & 7060 & 570 & 23026 & 1859 \\
\hline 870 & 300 & 29.8 & 12 & 0.310 & 0.003 & 6960 & 550 & $23 \quad 229$ & 1836 \\
\hline 900 & 300 & 29.8 & 19 & 0.310 & 0.004 & 6810 & 500 & 23126 & 1698 \\
\hline 930 & 300 & 29.5 & 25 & 0.310 & 0.006 & 6320 & 450 & 23340 & 1662 \\
\hline 960 & 300 & 29.5 & 30 & 0.310 & 0.007 & 5840 & 430 & $23 \quad 372$ & 1721 \\
\hline 990 & 300 & 29.5 & 33 & 0.310 & 0.008 & 5670 & 400 & 23895 & 1686 \\
\hline 1260 & 400 & 28.6 & 30 & 0.310 & 0.007 & 5120 & 520 & 20011 & 2032 \\
\hline 1290 & 400 & 28.3 & 28 & 0.310 & 0.006 & 5350 & 560 & 20141 & 2108 \\
\hline 1320 & 400 & 28.3 & 27 & 0.310 & 0.006 & 5310 & 530 & 19700 & 1966 \\
\hline 1350 & 500 & 27.7 & 24 & 0.310 & 0.005 & 7500 & 600 & 26382 & 2111 \\
\hline 1380 & 500 & 27.7 & 24 & 0.310 & 0.005 & 7530 & 600 & 26487 & 2111 \\
\hline 1410 & 500 & 28.3 & 25 & 0.310 & 0.005 & 7390 & 700 & $26 \quad 644$ & 2524 \\
\hline 1440 & 500 & 28.9 & 27 & 0.310 & 0.006 & 6950 & 600 & $26 \quad 124$ & 2255 \\
\hline 1470 & 500 & 29.2 & 29 & 0.310 & 0.007 & 6780 & 600 & 26483 & 2344 \\
\hline 1500 & 500 & 29.5 & 31 & 0.310 & 0.007 & 6570 & 600 & 26742 & 2442 \\
\hline 1530 & 500 & 29.5 & 33 & 0.310 & 0.008 & 6230 & 600 & $26 \quad 255$ & 2529 \\
\hline 1560 & 500 & 29.8 & 34 & 0.310 & 0.008 & 6060 & 600 & 26262 & 2600 \\
\hline 1590 & 500 & 29.8 & 35 & 0.310 & 0.008 & 6050 & 590 & 26714 & 2605 \\
\hline 1620 & 500 & 29.8 & 37 & 0.310 & 0.009 & 5720 & 600 & 26250 & 2753 \\
\hline 1650 & 600 & 29.8 & 38 & 0.310 & 0.009 & 7650 & 700 & $35 \quad 811$ & 3277 \\
\hline 1680 & 600 & 29.8 & 39 & 0.310 & 0.009 & 7480 & 700 & 35733 & 3344 \\
\hline 1710 & 600 & 29.8 & 40 & 0.310 & 0.009 & 7330 & 700 & 35750 & 3414 \\
\hline 1740 & 600 & 29.8 & 40 & 0.310 & 0.009 & 7300 & 600 & $35 \quad 604$ & 2926 \\
\hline 1770 & 600 & 29.8 & 41 & 0.310 & 0.010 & 7080 & 600 & $35 \quad 271$ & 2989 \\
\hline 1800 & 600 & 29.8 & 41 & 0.310 & 0.010 & 7210 & 600 & 35918 & 2989 \\
\hline 1830 & 600 & 29.8 & 42 & 0.310 & 0.010 & 6940 & 600 & $35 \quad 330$ & 3054 \\
\hline 1860 & 600 & 29.5 & 42 & 0.310 & 0.010 & 7200 & 600 & $36 \quad 120$ & 3010 \\
\hline 1890 & 600 & 29.8 & 42 & 0.310 & 0.010 & 6920 & 600 & $35 \quad 229$ & 3054 \\
\hline 1920 & 600 & 29.5 & 43 & 0.310 & 0.010 & 7080 & 600 & $36 \quad 289$ & 3075 \\
\hline
\end{tabular}


Table 2 - continued

\begin{tabular}{|c|c|c|c|c|c|c|c|c|c|}
\hline $\begin{array}{l}\text { Experimental } \\
\text { time } \\
(\mathrm{min})\end{array}$ & $\begin{array}{c}\text { Experimental } \\
\text { temperature } \\
\left({ }^{\circ} \mathrm{C}\right)\end{array}$ & $\begin{array}{c}\text { Air } \\
\text { temperature } \\
\left({ }^{\circ} \mathrm{C}\right)\end{array}$ & $\begin{array}{c}\text { Relative } \\
\text { humidity } \\
(\%)\end{array}$ & $\begin{array}{c}\text { Correction } \\
\text { factor } \\
D\end{array}$ & $\begin{array}{l}\mathrm{gH}_{2} \mathrm{O} \\
(\mathrm{g})\end{array}$ & $\begin{array}{c}{ }^{220} \mathrm{Rn} \\
\text { raw data } \\
\left(\mathrm{Bq} \mathrm{m}^{-3}\right)\end{array}$ & $\begin{array}{c}2 \sigma \\
\text { error } \\
\left(\mathrm{Bq} \mathrm{m}^{-3}\right)\end{array}$ & $\begin{array}{c}{ }^{220} \mathrm{Rn} \\
\text { corrected data } \\
\left(\mathrm{Bq} \mathrm{m}^{-3}\right)\end{array}$ & $\begin{array}{c}2 \sigma \\
\text { error } \\
\left(\mathrm{Bq} \mathrm{m}^{-3}\right)\end{array}$ \\
\hline 1950 & 700 & 29.8 & 43 & 0.310 & 0.010 & 7440 & 700 & $39 \quad 150$ & 3684 \\
\hline 2010 & 700 & 29.5 & 44 & 0.310 & 0.010 & 7510 & 700 & 39692 & 3700 \\
\hline 2040 & 700 & 29.8 & 44 & 0.310 & 0.010 & 7340 & 700 & 39209 & 3739 \\
\hline 2070 & 700 & 29.5 & 44 & 0.310 & 0.010 & 7390 & 600 & 39058 & 3171 \\
\hline 2160 & 700 & 29.5 & 45 & 0.310 & 0.010 & 7370 & 600 & 39536 & 3219 \\
\hline 2190 & 700 & 29.5 & 45 & 0.310 & 0.010 & 7310 & 600 & $39 \quad 214$ & 3219 \\
\hline 2220 & 700 & 29.5 & 45 & 0.310 & 0.010 & 7330 & 600 & 39321 & 3219 \\
\hline
\end{tabular}

characterized by a higher activity and a shorter half-life (56 s compared to $3.82 \mathrm{~d}$ ) was used (Tables 1 and 2). This allowed to reach rapidly the equilibrium activity and to respond quickly to any change of experimental condition affecting thoron emission rate. Measured thoron values $\left({ }^{220} \mathrm{Rn}_{M}\right)$ were corrected for the decay $(D)$ occurred during gas transport through the circuit and for the effect of high absolute humidity onto the efficiency of the silicon detector ( $\mathrm{AH})$, according to the following equation:

${ }^{220} \mathrm{Rn}={ }^{220} \mathrm{Rn}_{M} / D \times \mathrm{AH}$

The correction for $D$ was obtained from the value of the air flow rate through the circuit $\left(0.71 \mathrm{~min}^{-1}\right)$, directly measured using a flowmeter, the volume of the experimental circuit placed upstream of the radon monitor (from 1.43 to 2.531 , depending on the volume of the gas-drying unit) and the internal hose $(0.051)$ and filter volumes inside RAD7 (0.8 1), taking into consideration the thoron decay constant $\left(0.756 \mathrm{~min}^{-1}\right)$. The correction factor $D$ equals to 0.094 . The further correction accounts for the reduced efficiency (i.e. reduced electrostatic collection) of the silicon detector employed by RAD7, due to the neutralization of radon daughters ( ${ }^{218}$ Po ions) induced by water molecules which are present in the inner volume of RAD7. The corrective factor (AH) depends on the amount of water in the detection volume and the length of interaction of polonium atoms with water molecules, which impacts on the size of ${ }^{218}$ Po clusters and thus on the neutralization process. Specific corrections have been developed for the radon monitor employed in these experiments (De Simone et al. 2016) and properly applied on the basis of the mass of water molecules in RAD7 inner volume $\left(\mathrm{gH}_{2} \mathrm{O}\right)$. The general form of this correction is:

$\mathrm{AH}=-m \times \mathrm{gH}_{2} \mathrm{O}+c$

Where $m$ and $c$ are respectively the slope and the intercept of linear regression fit of efficiency data plotted versus $\mathrm{gH}_{2} \mathrm{O}$ (De Simone et al. 2016).

\subsection{Temperature dependence of radon emission rate}

The process of radon emission from rock is complex and depends on the physicochemical characteristics of radon and its surrounding (e.g. mineral composition, crystal structure, specific surface area, temperature, moisture and water content) including the radium source, radon emanation and radon migration (Tuccimei et al. 2011). The radon emission of rock is determined by the fraction atoms that escapes from the rock itself because most of these atoms produced by decay radium are stopped in the rock. When a radon atom escapes into the pore space of the material its migration is controlled by the flow properties of the pore fluid. Radon is chemically inert and its transport behaviour in the rock is dominated by migration through connected pores and cracks. Its short recoil length $\left(3 \times 10^{-8} \mathrm{~cm}\right)$, due to a short lifetime diffusion distance, implies that only atoms produced at the surface of grains, trapped within the space of pores and/or adsorbed by the free inner surface of microcracks can be released from rock to the surrounding medium. However, in a closed-loop experimental setup, changes in radon emission result in a new value of equilibrium activity as the temperature of the system increases or decreases. In particular, with increasing temperature, the number of effective collision of radon atoms with other molecules and grain boundaries is enhanced favouring the diffusion of radon through the pores of the material (Tuccimei et al. 2015). Since radioactive decay is essentially independent of temperature, the recoil process is weakly affected by temperature changes. On the other hand, as the diffusion coefficient is a function of temperature, the diffusion process is controlled by temperature changes. In this view, the temperature-dependent diffusion coefficient $D(T)$ (in $\mathrm{cm}^{2} \mathrm{~s}^{-1}$ ) can be described empirically by an equation with a non-linear Arrhenius behaviour (Glasstone et al. 1941; Shewmon 1963):

$D(T)=D_{0} \exp \left(-\frac{Q}{R T}\right)$

where $D_{0}\left(\mathrm{~cm}^{2} \mathrm{~s}^{-1}\right)$ is the empirical constant (i.e. pre-exponential factor) which depends on the number of diffusion paths and their availability for radon atom migration, $Q\left(\mathrm{~J} \mathrm{~mol}^{-1}\right)$ is the activation energy of diffusion and comprises the activation energy of the escape of radon atoms from the solid sample and the activation energy of the migration along diffusion paths in the solid, $R\left(8.314 \mathrm{~J} \mathrm{~mol}^{-1}\right.$ $\mathrm{K}^{-1}$ ) is the gas constant and $T(\mathrm{~K})$ is the temperature of the system. In the simplification that all situations considered for a single radon emission measurement are stationary (i.e. isothermal and isobaric), the overall material is homogeneous, and adsorption of radon to solid surfaces is negligible, the change in radon emission rate ( $E$ in arbitrary units) is expressed as the result of changes due to diffusion and obeys to the formulation (Megumi \& Mamuro 1973):

$E=k \sqrt{D_{0}} \exp -\frac{Q}{2 R T}$

where $k$ is described by the relationship (Flugge \& Zimens 1939):

$k=3 \sqrt{\frac{1}{\lambda r^{2}}}$

where $\lambda$ is the decay constant of radon $\left(2.1 \times 10^{-6}\right.$ and $11.3 \times 10^{-2}$ $\mathrm{s}^{-1}$ for ${ }^{222} \mathrm{Rn}$ and ${ }^{220} \mathrm{Rn}$, respectively) and $r$ is the radius $(\mathrm{cm})$ of an 


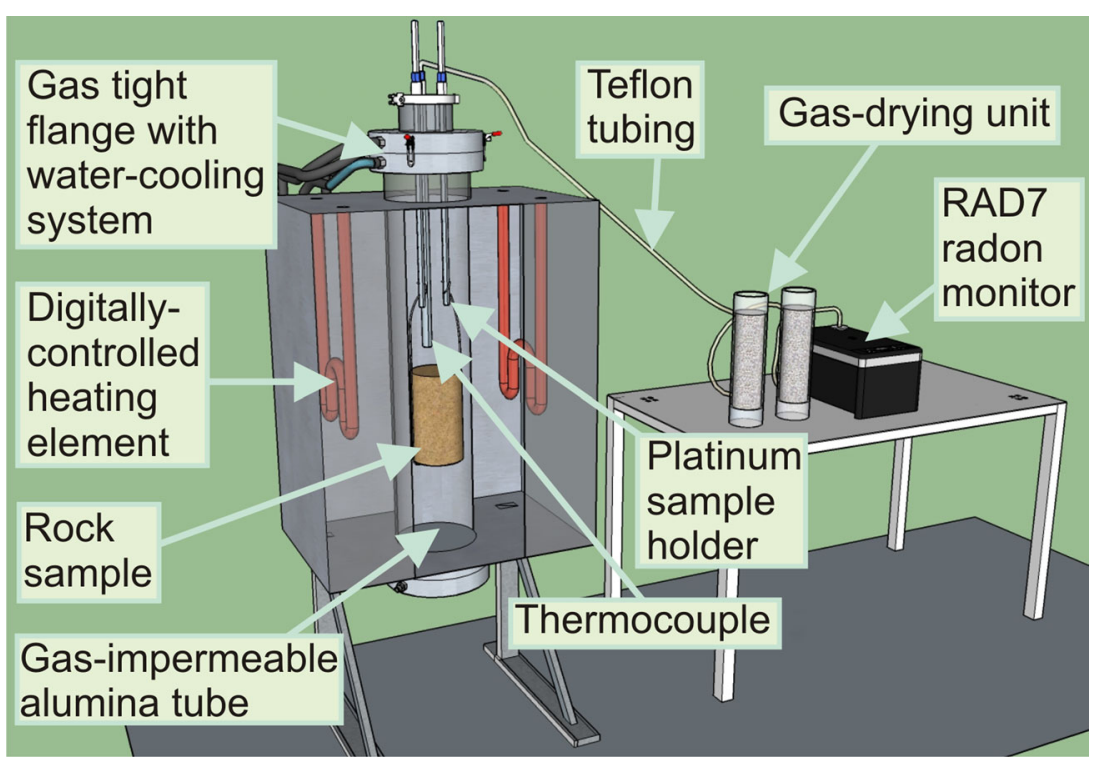

Figure 1. Schematic view of the experimental setup. A high temperature (up to $1800^{\circ} \mathrm{C}$ ) vertical furnace is equipped with a gas-impermeable alumina tube, gas tight flanges with a water-cooling system, digitally controlled $\mathrm{MoSi}_{2}$ heating elements and a Type $\mathrm{S}$ thermocouple. The cylindrical rock sample is suspended into the alumina tube through a platinum sample holder. A Teflon tube connects, in a closed-loop configuration, the alumina tube to a gas-drying unit filled with a desiccant and to a RAD7 radon monitor (Durridge Company Inc.).

hypothetical radioactive grain of the rock sample. Eqs (3) and (4) can be combined to obtain:

$E=k D_{0}^{\prime} \exp \left(-\frac{Q^{\prime}}{R T}\right)$

where $D_{0}^{\prime}=k \sqrt{D_{0}}$ and $Q^{\prime}=Q / 2$ (i.e. the experimental activation energy). This two parameters may be obtained experimentally from the plot $\ln E$ versus $1 / T$. The linear equation is expressed as (Beckman \& Balek 2002):

$\ln E=\ln D_{0}^{\prime}-\frac{Q^{\prime}}{R T}$

The value of $\ln D_{0}^{\prime}$ is derived as the intercept at $1 / T=0$ and the slope of the linear fit is given by:

$\frac{d \ln E}{d \frac{1}{T}}=-\frac{Q^{\prime}}{R}$

The values of $\ln D_{0}^{\prime}$ and $Q^{\prime}$ are calculated from the intercept and slope of the linear fit so that the diffusion coefficient $D(T)$ can be estimated as a function of temperature.

Eq. (7) has been experimentally derived by the regression analysis of ${ }^{220} \mathrm{Rn}$ data obtained after complete dehydration of TRSN1 at the target temperature of $800{ }^{\circ} \mathrm{C}$ (Table 1). In particular, the lack of mineral devolatilization reactions during cooling of TRSN1 from 800 to $100^{\circ} \mathrm{C}$ and the weak porosity change ( $\sim 7-51 \%$ ) suggest that the migration of radon atoms into the pore space of the material is controlled only by the effect of temperature on the number of effective collision of radon atoms with other molecules. In this framework, eq. (7) is described by the following regression fit $\left(R^{2}=0.962\right)$ :

$\ln E_{220 \mathrm{Rn}}=9.16-\frac{922.6}{T}$

where $\ln D_{0}^{\prime}=9.16$ and $Q^{\prime}=922.6$.

\subsection{Mineralogical and chemical analyses}

A detailed description of the methods used to perform mineralogical and chemical analyses of TRSN is reported in the Supporting Information. Overall, these analyses were conducted with an electron probe microanalyzer, a field emission gun-scanning electron microscopy, the X-ray powder diffraction (XRPD) technique, and thermogravimetric (TG), differential thermogravimetric (DTG) and differential scanning calorimetric (DSC) methods.

\section{A NOVEL EXPERIMENTAL SETUP FOR RADON MEASUREMENTS}

The experimental setup presented in this study has been developed at the HPHT Laboratory of Experimental Volcanology and Geophysics of the Istituto Nazionale di Geofisica e Vulcanologia (INGV) in Rome (Italy) and consists of a high temperature (up to $1800{ }^{\circ} \mathrm{C}$ ) vertical furnace equipped with a gas-impermeable alumina tube (Fig. 1). A cylindrical rock sample is suspended into the alumina tube through a platinum sample holder. Digitally controlled $\mathrm{MoSi}_{2}$ heating elements ensure a homogeneous hot zone along the entire length of the sample. The temperature is monitored by a factory-calibrated Type S (Pt90Rh10-Pt) thermocouple with uncertainty $\pm 3{ }^{\circ} \mathrm{C}$. Upper and lower gas tight flanges with a water-cooling system seal the alumina, preventing gas leakage. A Teflon tube (inserted into the upper flange) connects, in a closedloop configuration, the alumina tube to a gas-drying unit filled with a desiccant $\left(\mathrm{CaSO}_{4}\right.$ with $3 \% \mathrm{CoCl}_{2}$, as indicator) and to a RAD7 radon monitor (Durridge Company Inc.). A recirculating pump in the RAD7 moves the gas from the alumina tube through both the desiccant and inlet filter to a solid-state detector for alpha counting of radon and thoron progeny. The gas is recirculating continuously through the system and no fresh ambient air is pulled into the experimental setup. The electrostatic detector collects the charged ions and discriminates the electrical pulses generated by their alpha particles. This allows selecting only the short-lived ${ }^{218} \mathrm{Po}$ and ${ }^{216} \mathrm{Po}$ counting for a rapid determination of ${ }^{222} \mathrm{Rn}$ and ${ }^{220} \mathrm{Rn}$, respectively. 


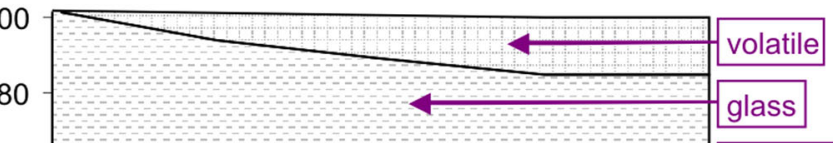

(c)
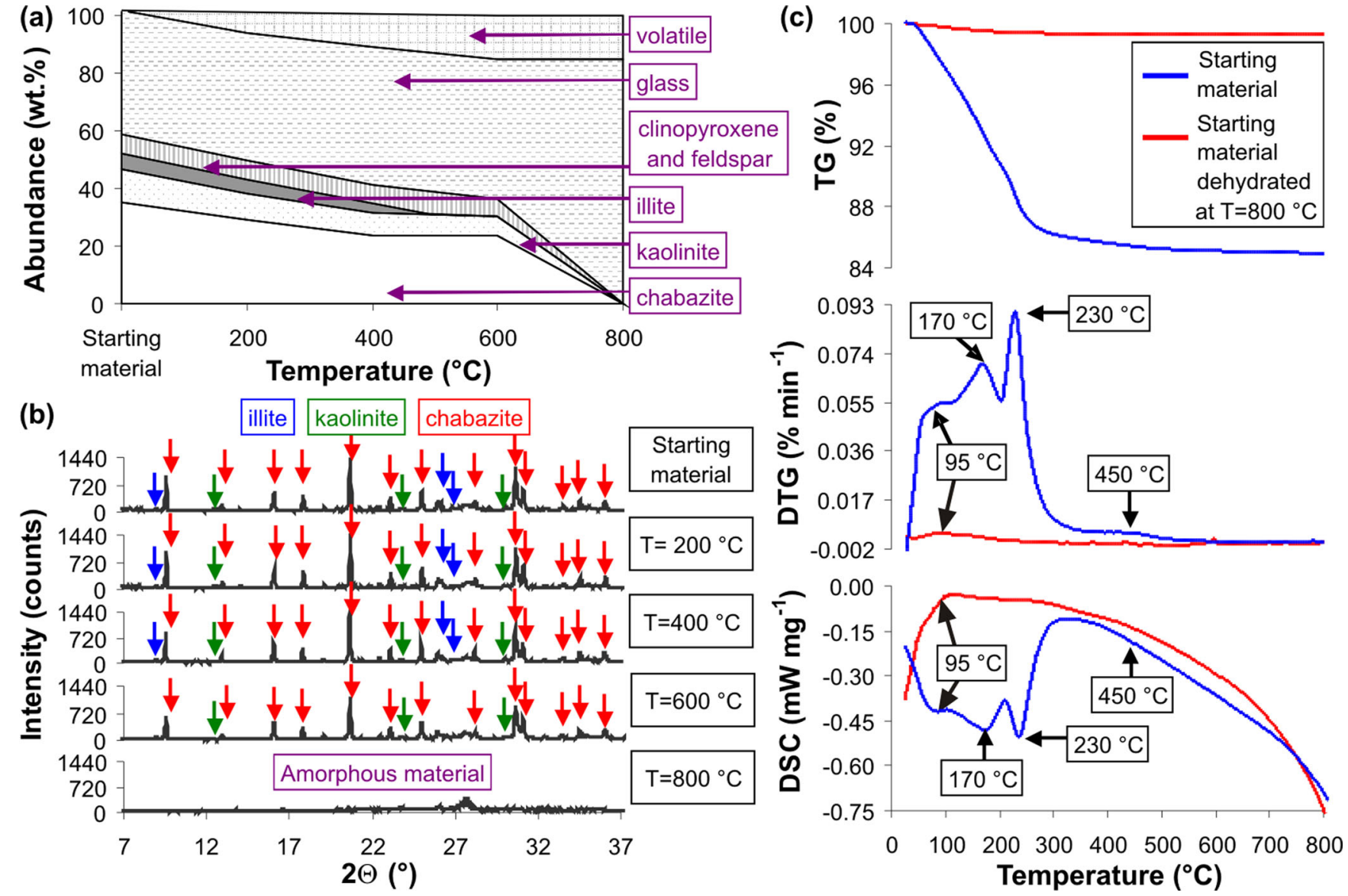

Figure 2. (a) Changes in the abundance of mineral phases, matrix glass and volatile release as a function of temperature. (b) X-ray powder diffraction (XRPD) data showing the stability of mineral phases with temperature. (c) Thermogravimetric (TG), differential thermogravimetric (DTG) and differential scanning calorimetric (DSC) data evidencing multiple dehydration events as the devolatilization reactions proceed.

The radioactive equilibrium between ${ }^{218} \mathrm{Po}$ and ${ }^{222} \mathrm{Rn}$ is achieved in $\sim 15$ min (i.e. $\sim 5$ times the half-life of ${ }^{218} \mathrm{Po}$ ), whereas the equilibrium between ${ }^{216} \mathrm{Po}$ and ${ }^{220} \mathrm{Rn}$ occurs in a few seconds due to the very short half-life of ${ }^{216} \mathrm{Po}(0.15 \mathrm{~s})$. Therefore, the activity of ${ }^{220} \mathrm{Rn}$ has been monitored during the experiments considering that the behaviour of this signal is comparable with the activity of ${ }^{222} \mathrm{Rn}$ due to the lack of isotopic fractionation between heavy radon and thoron isotopes (i.e. low-mass difference of $0.01 \%$ ).

\section{TRACKING THE DEVOLATILIZATION REACTIONS}

Chabazite (35 wt.\%) is the most abundant mineral phase of the starting material (Fig. 2a), followed by clay minerals (14 wt.\%) and igneous phenocrysts ( $8 \mathrm{wt} . \%$ ) dispersed in the matrix glass (43 wt.\%). As the temperature increases, the abundance of mineral phases decreases counterbalanced by an increasing glass content and volatile release due to progressive dehydration phenomena (Fig. 2a).

XRPD analysis shows that the crystalline structure of illite is dissolved early at $T>400{ }^{\circ} \mathrm{C}$ (Fig. 2b), responding to the lowtemperature decomposition of mineral (Araújo et al. 2004). At $T=700{ }^{\circ} \mathrm{C}$, the crystalline structures of kaolinite and chabazite are still resolved (see XRPD data reported in the Supporting Information). At $T=800$, XRPD patterns show the occurrence of non-crystalline material (amorphous glass) accompanied by faint and broad Bragg reflections indicative of the total dissolution of $\mathrm{H}_{2} \mathrm{O}$-bearing minerals (Fig. 2b).

TG analysis of the powdered starting material indicates that, as all the devolatilization reactions cease at $T=800{ }^{\circ} \mathrm{C}$, the total amount of volatile released is $\sim 15$ wt.\% (blue curve in Fig. $2 \mathrm{c}$ ). DTG and DSC curves evidence, by a single peak at $T=95^{\circ} \mathrm{C}$, the effect of moisture adsorbed on the powder grains $\left(2.9\right.$ wt.\% $\left.\mathrm{H}_{2} \mathrm{O}\right)$ during exposure to atmospheric humidity (Fig. 2c). This is also confirmed by the recurrence of the same moisture peak after complete dehydration of the rock powder at $T=800{ }^{\circ} \mathrm{C}$ (red curve in Fig. 2c). However, the intensity of this peak is low $\left(0.3 \mathrm{wt} . \% \mathrm{H}_{2} \mathrm{O}\right)$ due to the total dissolution of chabazite that, at $T<100{ }^{\circ} \mathrm{C}$, exhibits a high adsorption/desorption capacity wherein the crystal lattice undergoes no changes (Simonot-Grange 1979). The total moisture release occurs in $\sim 10$ min (see TG data in the Supporting Information) that is one order of magnitude lower than that (120 min) selected for radon measurements, in order to ensure total removal of atmospheric humidity from the rock sample. As the temperature increases, multiple devolatilization events for chabazite are identified as endothermic peaks at $T=170,230$ and $450^{\circ} \mathrm{C}$, wherein the crystal lattice undergoes reversible and irreversible changes (Barrer \& Langley 1958; Passaglia et al. 1990; Neuhoff \& Wang 2007) during intracrystalline $\mathrm{H}_{2} \mathrm{O}$ release of 4.1, 5.7 and $1.8 \mathrm{wt} . \%$, respectively (Fig. 2c). Due to the low modal content of clay minerals (Fig. 2a), the endothermic escape of interlayer $\mathrm{H}_{2} \mathrm{O}$ is not resolved at $T=140$ $200{ }^{\circ} \mathrm{C}$ (Araújo et al. 2004) and $T=540{ }^{\circ} \mathrm{C}$ (Brindley et al. 1967) for illite and kaolinite, respectively (Fig. 2c). The glass transition 


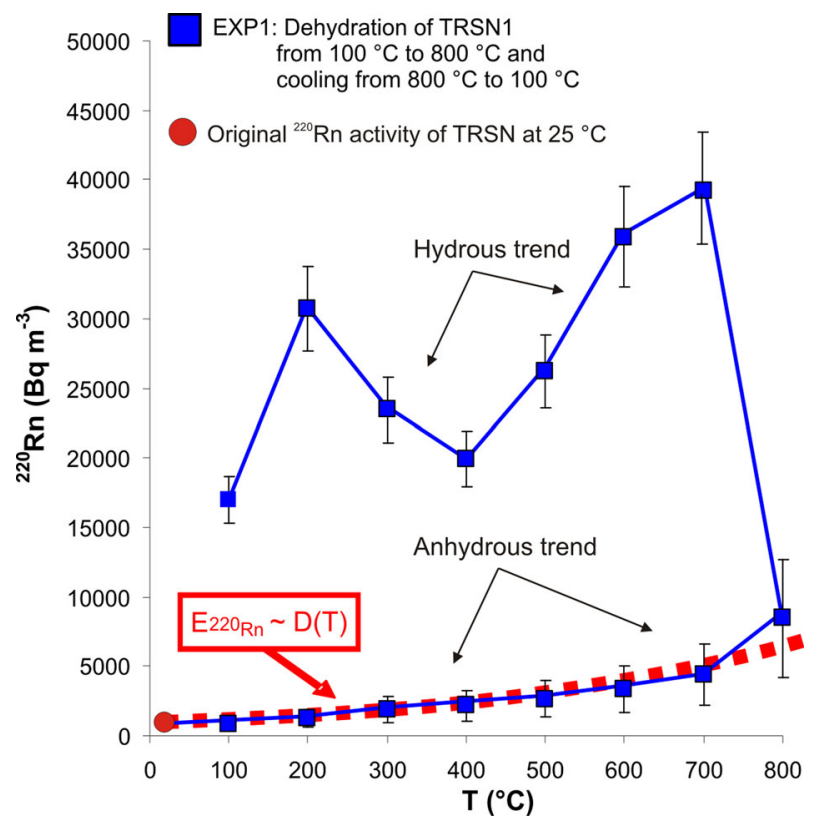

Figure 3. Results from EXP1 plotted in a temperature versus ${ }^{220} \mathrm{Rn}$ diagram. Dehydration EXP1 consists of TRSN1 sample heated in eight steps of 100, $200,300,400,500,600,700$ and $800^{\circ} \mathrm{C}$ and then cooled in seven steps of $700,600,500,400,300,200$ and $100{ }^{\circ} \mathrm{C}$. Dehydration EXP2 consists of TRSN2 heated in four steps of $100,170,230$ and $450{ }^{\circ} \mathrm{C} .{ }^{220} \mathrm{Rn}$ activity is the average of four measurement cycles for each temperature reported in Table 1.

region of phonolitic melts is generally encountered at $T=450$ $650{ }^{\circ} \mathrm{C}$ (Giordano et al. 2008) but, within this temperature range, TG data indicate a minimum volatile release of $\sim 0.5$ wt. $\% \mathrm{H}_{2} \mathrm{O}$ (Fig. 2c). Therefore, with the exception of the adsorbed moisture, both the matrix glass and clay minerals do not contribute significantly to the overall $\mathrm{H}_{2} \mathrm{O}$ release that, in turn, is almost entirely controlled by the thermal dissolution of chabazite (Fig. 2c).

\section{RESULTS AND DISCUSSION}

The dehydration EXP1 consisted of an heating stage from 100 to $800{ }^{\circ} \mathrm{C}$ and a subsequent cooling stage down to $100^{\circ} \mathrm{C}$ (Fig. 3). At the beginning of the heating stage, the radon emission from TRSN1 is mostly dependent on the moisture adsorbed by chabazite during exposure to the atmospheric humidity. At $T=100^{\circ} \mathrm{C}$, the outgassing of moisture increases the radon signal of one order of magnitude with respect to the anhydrous material (Fig. 3). After the release of moisture, radon emission remains relatively high due to the onset of mineral devolatilization reactions. Two radon peaks are observed at $T=200$ and $700{ }^{\circ} \mathrm{C}$ (Fig. 3), being separated by a moderate decrease of radon emission at $T=400^{\circ} \mathrm{C}$ and an abrupt drop at $T=800^{\circ} \mathrm{C}$. A direct consequence of the multiple dehydration events of chabazite (Fig 2c) is that the radon signal does not monotonically increases with temperature (Fig. 3). Consequently, the radon emission rate cannot be interpreted and modelled in the frame of a temperaturedependent diffusion model (Beckman \& Balek 2002; Voltaggio et al. 2006). In contrast, as TRSN 1 is cooled from 800 to $100{ }^{\circ} \mathrm{C}$, the radon emission monotonically decreases with temperature (Fig. 3) due to the total dissolution of $\mathrm{H}_{2} \mathrm{O}$-bearing minerals (Fig. 2a) and the completion of all devolatilization reactions (Fig. 2b). Importantly, the regression analysis of these anhydrous data (red dashed line in Fig. 3) indicates that changes in radon emission rate $E_{220 \mathrm{Rn}}$ are

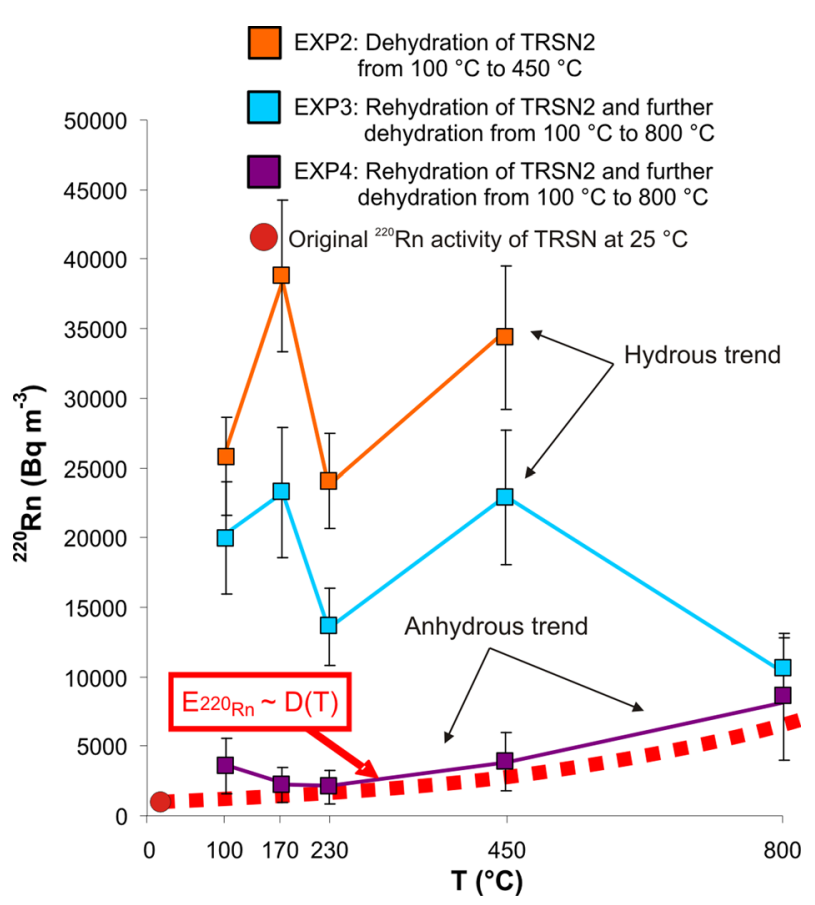

Figure 4. Results from EXP3 and EXP4 plotted in a temperature versus ${ }^{220} \mathrm{Rn}$ diagram. Hydration/dehydration EXP3 consists of the rehydrated TRSN2 sample that is reheated at the same conditions of EXP2 with a further step at $800{ }^{\circ} \mathrm{C}$. Hydration/dehydration EXP4 consists of the rehydrated TRSN2 sample that is rehydrated at the same conditions of EXP3.

${ }^{220} \mathrm{Rn}$ activity is the average of four measurement cycles for each temperature reported in Table 1.

proportional to the dependence of radon diffusion coefficient $D(T)$ on the experimental temperature (Scarlato et al. 2013).

The dehydration EXP2 was designed to investigate the multiple dehydration events of chabazite evidenced by DTG and DSC curves (Fig. 2c). Coherently with the mineral devolatilization products, high radon emissions are measured for TRSN2, in correspondence of two chabazite endothermic peaks at $T=170$ and $4500^{\circ} \mathrm{C}$ (Fig. 4). Surprisingly, when the maximum dehydration peak of chabazite in encountered at $T=230{ }^{\circ} \mathrm{C}$ (Fig. 2c), a decrease in radon signal is measured (Fig. 4). An almost identical trend is found for the replicated EXP3 in which TRSN2 was rehydrated before heating (Fig. 2c). Note that the overall radon signal measured for EXP3 is lower than that observed for EXP2 (Fig. 2c), reflecting the reduced $\mathrm{H}_{2} \mathrm{O}$ sorption capacity of chabazite caused by structural changes at $T>175{ }^{\circ} \mathrm{C}$ (Fialips et al. 2005; Neuhoff \& Wang 2007). During EXP3, the temperature was also increased up to $800{ }^{\circ} \mathrm{C}$ in order to achieve complete rock dehydration. The total dissolution of chabazite caused that TRSN2 rehydration was minimum and limited to weak moisture adsorption on the pore surfaces. This almost anhydrous material was reheated during EXP4. Radon measurements evidence as the signal monotonically increases with increasing temperature, resembling the trend observed for EXP1 (Fig. 2c) and according to the regression model $E_{220 \mathrm{Rn}} \sim D(T)$.

It is worth noting that TG, DTG and DSC curves (Fig 2c) reflect the release of $\mathrm{H}_{2} \mathrm{O}$ from the powdered starting material in which the dehydration of chabazite occurs rapidly due to the high reaction rate of its small particles. Conversely, adsorption phenomena take place through the solid rock samples (i.e. TRSN1 and TRSN2), causing that volatiles cannot rapidly escape through the interconnected pores of the medium (Fig. 4). The grain surfaces serve as traps for gas molecules by adsorbing a fraction of their kinetic 
energy and by retaining a part of them in the pore space (Beckman $\&$ Balek 2002). The molecules may escape from the traps only when the temperature of the system exceeds greatly the activation energy of diffusion favouring gas mobility (Balek \& Beckman 2005). The time lag between the early chabazite devolatilization and subsequent gas release through the interconnected pores of the rock implies that the radon signal cannot be univocally associated to the endothermic peaks of chabazite. First, a fairly positive correlation is found between the enhanced radon emission (Fig. 4) and the dehydration events at $T=170$ and $450{ }^{\circ} \mathrm{C}$ (Fig. 2c). Second, the most energetic $\mathrm{H}_{2} \mathrm{O}$ dehydration peak of chabazite at $T=230{ }^{\circ} \mathrm{C}$ (Fig. 2c) corresponds to a moderate drop of the radon signal (Fig. 4). For a minor part, this different behaviour can be addressed to annealing effects at $T>200{ }^{\circ} \mathrm{C}$ that lower the level of natural radiation damage in mineral grains (Barretto 1975). Thermally induced structural reorganizations may gradually suppress the structural defects of the crystal lattice, thus reducing the overall radon emanation of the rock (Beirau et al. 2012, 2016). However, most of the radon decrease is caused by adsorption phenomena taking place when $\mathrm{H}_{2} \mathrm{O}$ molecules in excess start to fill the interconnected pores of the medium, limiting significantly the radon transport (Megumi \& Mamuro 1974). In correspondence of the maximum dehydration peak of chabazite (Fig. 2c), a fraction of $\mathrm{H}_{2} \mathrm{O}$ is adsorbed on the interstitial surface of the rock and condensed by capillary force in the pore space (Tanner 1978; Shweikani et al. 1995). This is also qualitatively evidenced by the onset of $\mathrm{H}_{2} \mathrm{O}$ condensation in the Teflon tube and gas-drying unit of the experimental setup. Notably, the mean vapour-adsorption curve obtained for tuff rocks indicates that the amount of adsorbed $\mathrm{H}_{2} \mathrm{O}$ increases significantly at a relative humidity of about $70-75 \%$ (Benavente et al. 2009). The exponential growth rate of vapour adsorption is related to an increase in $\mathrm{H}_{2} \mathrm{O}$ film on the surface layer of rock pores and the beginning of capillarity $\mathrm{H}_{2} \mathrm{O}$ condensation (Papachristodoulou et al. 2007; Prasad et al. 2012; FernandezCortes et al. 2013). As a result, condensed $\mathrm{H}_{2} \mathrm{O}$ obstructs the direct passage of radon, hampering its diffusivity in the medium (Etiope \& Martinelli 2002). Since the starting material is prevalently composed of a silica-rich glass matrix (Fig. 2a; see also microprobe data reported in the Supporting Information), $\mathrm{OH}$ groups produced by chabazite dehydration can be readily bounded with $\mathrm{Si}$ atoms on the glass surface (i.e. hydroxyl coverage, Zhuravlev 2000). These $\mathrm{OH}$ groups attach on the glassy grains and act as centres of molecular adsorption (Tomozawa 1985). The temperature range for removing physically the adsorbed $\mathrm{H}_{2} \mathrm{O}$ is $450-700^{\circ} \mathrm{C}$ and the maximum desorption peak is centred at $T=700{ }^{\circ} \mathrm{C}$ (Frisch \& Giess 1990). Coherently with the removal of hydroxyl groups from the matrix glass, EXP1 shows a net increase in the radon signal at $T>400{ }^{\circ} \mathrm{C}$ with a maximum value at $T=700{ }^{\circ} \mathrm{C}$ (Fig. 3).

Positive radon anomalies are frequently addressed to repeated cycles of stress due to volcano inflation/deflation and increasing magmatic pressures leading to the opening or reactivation of fractures (La Delfa et al. 2012; Neri et al. 2006). Uniaxial deformation experiments conducted by previous studies (Tuccimei et al. 2010, 2015; Scarlato et al. 2013) on the same TRSN material indicate that, when the stress condition increases up to rock failure, new emanation surfaces are created in the form of macroscopic faults. Under such circumstances, most of the gas trapped within the material escapes and the radon emission increase up to $72 \%$ of the initial value measured for the intact rock. On the other hand, lava flowing onto the surface or dyke intruding within the volcanic edifice may release heat to the surrounding country rocks and produce thermal gradients of several hundreds of Celsius degrees (Mollo et al. 2012; Vetere et al. 2015). At $T=100^{\circ} \mathrm{C}$, the outgassing of moisture adsorbed on the chabazite grains causes that the radon signal increases by $\sim 1600 \%$ (i.e. from $\sim 1000$ to $\sim 17000 \mathrm{~Bq} \mathrm{~m}^{-3}$; see Exp1 in Fig. 3) with respect to the anhydrous material. When the temperature increases, the radon emission further increases due the onset of mineral devolatilization reactions. The early dehydration event of chabazite at $170{ }^{\circ} \mathrm{C}$ causes that the radon signal increases by $\sim 1800 \%$ (i.e. from $\sim 2000$ to $\sim 38000 \mathrm{~Bq} \mathrm{~m}^{-3}$; see Exp2 in Fig. 4) with respect to the anhydrous condition. The overall dehydration phenomena produce radon emissions two orders of magnitude higher than those measured during rock deformation, microfracturing and failure. In this view, any potential deformation-dependent radon emission at the ground surface can be overprinted by the effect of devolatilization reactions in the ground due to temperature changes.

There is general consensus that radon measurements at active volcanoes environments are related to changes in the local structure of the substrate, especially in areas characterized by dyke complexes, active conduits and fracture zones (Giammanco et al. 2007; Neri et al. 2016). In these scenarios, the radon signal is subjected to a wide spectrum of perturbation phenomena, such as deposition of radioactive elements, soil penetrability, meteorological conditions, tectonic structures, thermal gradients, fumarolic activities and $\mathrm{CO}_{2}$ fluxes (Roca et al. 2004; Banerjee et al. 2011; Schubert \& Paschke 2015). The experiments presented in this study evidence as thermally induced devolatilization reactions act as a complementary perturbation mechanism to increase remarkably the radon activity. Mineral dehydration events in volcanic areas produce radon anomalies in the background signal, consistently with the notion that the radon emission is strictly related to an increased degassing or thermally induced advection (Gervino et al. 2004). Indeed, high radon values are frequently modelled in terms of enhanced heat flow and related stream discharge or stress-induced microfracturing giving rise to anomalies in surface radon emissions (Gervino et al. 2004). In this framework, mineral devolatilization reactions will contribute significantly to produce radon emissions spatially heterogeneous and non-stationary in time, resulting in a transient state dictated by temperature gradients and the carrier effects of subsurface gases (Heiligmann et al. 1997; Kotsarenko et al. 2016; Neri et al. 2016).

In order to evidence to what extent laboratory experiments from this study are representative for thermal gradients operating in intrusive magma bodies, numerical simulations of heat flows in and around magmatic intrusions have been performed. When an intrusive body cools, the total enthalpy of the melt is released to the surrounding host rock in a regular continuum of heat loss described by the heat equation (Blundy et al. 2006; Whittington et al. 2009). The conductive cooling and heating conditions of a cylindrical rock volume are calculated through 2-D numerical simulations based on an explicit finite-difference scheme where the thermal path (TP) is determined by the variation of thermal gradient with time and the variation of thermal diffusivity with temperature (cf. Wohletz et al. 1999, and references therein). These computations focus on small magmatic intrusions $\left(0.0003-0.1 \mathrm{~km}^{3}\right)$, as typically observed when magmas rising from depth interact with the subvolcanic rocks at very shallow levels $(<1 \mathrm{~km})$ or, alternatively, inject within the volcanic edifice possibly feeding eruptions (Mordret et al. 2010; Coppola et al. 2017). The following boundary conditions were used for the calculations: (i) the size and volume of the intrusion and host rock are $16 \mathrm{~m}$ (width) $\times 24 \mathrm{~m}$ (height) and $0.0048 \mathrm{~km}^{3}$, and $36 \mathrm{~m}$ (width) $\times 36 \mathrm{~m}$ (height) and $0.0037 \mathrm{~km}^{3}$, respectively (ii) an initial temperature, bulk density, specific heat and thermal conductivity of $1180{ }^{\circ} \mathrm{C}, 2700 \mathrm{~kg} \mathrm{~m}^{-3}, 1150 \mathrm{~J} \mathrm{~kg}^{-1} \mathrm{~K}$ and $30{ }^{\circ} \mathrm{C}, 1.8 \mathrm{~W} \mathrm{mK}^{-1}$ and 

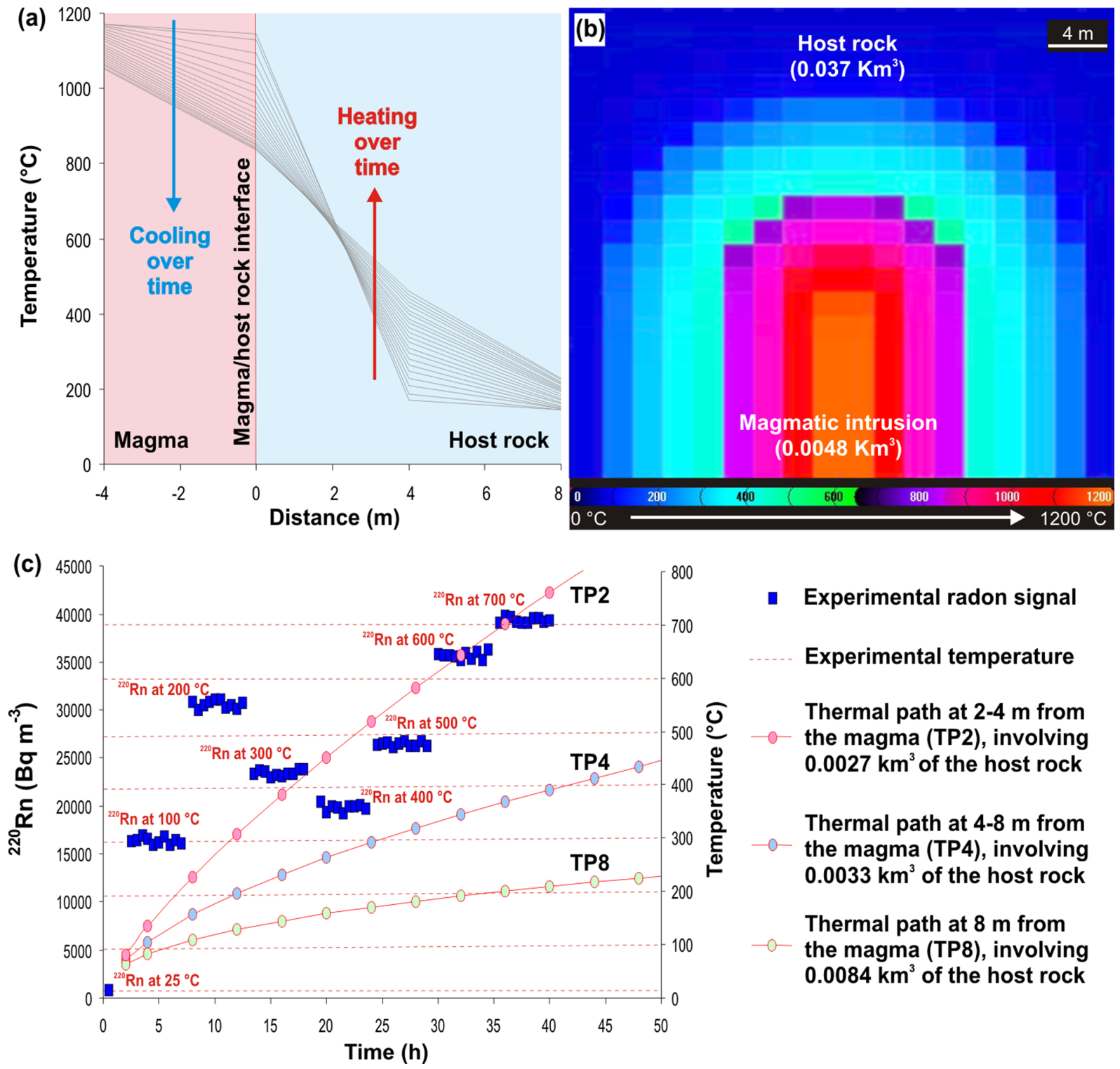

- Experimental radon signal

Experimental temperature

Thermal path at 2-4 $\mathrm{m}$ from the magma (TP2), involving $0.0027 \mathrm{~km}^{3}$ of the host rock

Thermal path at 4-8 $\mathrm{m}$ from the magma (TP4), involving $0.0033 \mathrm{~km}^{3}$ of the host rock

Thermal path at $8 \mathrm{~m}$ from the magma (TP8), involving $0.0084 \mathrm{~km}^{3}$ of the host rock

Figure 5. Thermal effect of an intruding magma on the surrounding rock. (a) Thermal gradient profiles from data modelling evidence that variable cooling/heating paths are encountered as a function of both the time of the intrusion and the distance from the magma/host rock interface. (b) The temperature distribution corresponding to the final simulation is showed for the intrusion and the country rock. (c) Experimental radon data from Table 2 are compared with the thermal paths (TP) obtained at distances of 2-4 (TP2), 4-8 (TP4) and 8 (TP8) $\mathrm{m}$ from the intruding magma (c).

of $2300,1150 \mathrm{~J} \mathrm{~kg}^{-1} \mathrm{~K}$ and $3 \mathrm{Wm}^{-1} \mathrm{~K}$ for the intruding magma and host rock, respectively (data from Lange \& Carmichael 1987; Wohletz et al. 1999; Mollo et al. 2015) and (iii) a negligible value for the latent heat of crystallization and heat convective transfer (see also Wohletz et al. 1999 for further details). Fig. 5(a) shows that the temperature variation of the system is determined by the progressive cooling of the intruding magma counterbalanced by the increasing temperature of the surrounding rock. Thermal gradient profiles plotted in Fig. 5(b) evidence that variable cooling/heating paths are encountered as a function of both the time of the intrusion and the distance from the magma/host rock interface. The heat dissipation proceeds over time from the hot magma toward the cold host rock, producing distinct TP. Intuitively, as the distance from the magma/host rock increases, the volume of the host rock is progressively heated at lower rates. In Fig. 5(c), experimental radon data from Table 2 are compared with the TP obtained at distances of 2-4 (TP2), 4-8 (TP4) and 8 (TP8) $\mathrm{m}$ from the intruding magma. TP2, TP4 and TP 8 correspond to the conductive heat propagating in host rock volumes of $0.0027,0.0033$ and $0.0084 \mathrm{~km}^{3}$, respectively. With respect to the total volume of $0.0037 \mathrm{~km}^{3}$, TP2, TP4 and TP8 progressively heat the host rock for 7,9 and $23 \%$ in volume. Fig. 5(c) shows that, after a certain time, each TP trajectory intercepts the experimental temperature at which the radon signal was measured in laboratory. For example, after $\sim 2 \mathrm{~h}, \mathrm{TP} 2$ intercepts the experimental temperature of $100{ }^{\circ} \mathrm{C}$ (Fig. 5c), corresponding to radon signal of $\sim 17000 \mathrm{~Bq} \mathrm{~m}^{-3}$. Similarly, after $\sim 4 \mathrm{~h}$, both TP4 and TP8 encounter the same experimental temperature of $100{ }^{\circ} \mathrm{C}$ (Fig. 5c). Extrapolating these data over the temporal and spatial scales of magmatic processes, it can be concluded that, in less than $40 \mathrm{~h}$, at least $39 \%$ of the host rock volume is exposed to $T>200{ }^{\circ} \mathrm{C}$. This thermal condition causes volatile release due to dehydration phenomena that increase the radon signal of one order of magnitude 
relative to the radon activity measured at $25^{\circ} \mathrm{C}$ from the undegassed material (Fig. 5c).

\section{CONCLUSIONS}

Anomalous radon emissions in active volcanic areas can reflect complex physicochemical changes of rocks and their constituents as a function of temperature. Thermally induced devolatilization reactions of common zeolite minerals produce a non-equilibrium condition for the activity of radon. The release of $\mathrm{H}_{2} \mathrm{O}$ during zeolite dehydration contributes significantly in enhancing the radon signal. This holds below a dehydration threshold value corresponding to the maximum rate of the mineral thermal decomposition. Above this threshold, $\mathrm{H}_{2} \mathrm{O}$ molecules in excess are adsorbed on the interstitial surface of the rock, by decreasing the radon emanation power of the medium. Thermally induced devolatilization reactions may act as perturbation mechanisms that may contribute significantly to produce radon emissions spatially heterogeneous and non-stationary in time. This process is particularly effective during ascent of small magma batches from depth that, at very shallow levels, interact with the subvolcanic rocks.

\section{ACKNOWLEDGEMENTS}

The authors would like to thank Joachim Wassermann for his constructive suggestions and editorial work. This work has been greatly improved by the helpful comments of Heiko Woith. Stimulating criticisms from an anonymous reviewer were also appreciated. This study was supported by Ministero dell'Istruzione, dell'Università e della Ricerca (MIUR), Premiale project-NoRth: New hORizons of the Technology applied to experimental researches and geophysical and volcanological monitoring. The research activities of the HPHT laboratory of the Istituto Nazionale di Geofisica e Vulcanologia (INGV) were supported by the European Observing System Infrastructure project (EPOS). GI was supported by 'Fondi Ateneo' of the University G. d'Annunzio.

\section{REFERENCES}

Araújo, J.H., Silva, N.F., Acchar, W. \& Gomes, U.U., 2004. Thermal decomposition of illite, Mater. Res., 7, 359-361.

Balek, V. \& Beckman, I.N., 2005. Theory of emanation thermal analysis XII. Modelling of radon diffusion release from disordered solids on heating, J. Therm. Anal. Calorim., 82, 755-759.

Banerjee, K.S., Basu, A., Guin, R. \& Sengupta, D., 2011. Radon (222Rn) level variations on a regional scale from the Singhbhum Shear Zone, India: a comparative evaluation between influence of basement U-activity and porosity, Radiat, Phys. Chem., 80, 614-619.

Barretto, P.M.C., 1975. Radon-222 emanation characteristics of rocks and minerals, Int. At. Energy Agency, Vienna, Austria, 188 p. IAEA-PL-505/1.

Barrer, R.M. \& Langley, D.A., 1958. Reactions and stability of chabazitelike phases. Part I. Ion-exchanged forms of natural chabazite, J. Chem. Soc., 1958, 3804-3811.

Baskaran, M., 2016. Radon: A Tracer for Geochemical Exploration: Radon: A Tracer for Geological, Geophysical and Geochemical Studies, ed. Baskaran, M., p. 260, Springer International Publishing.

Beckman, I.N. \& Balek, V., 2002. Theory of emantion thermal analysis XI. Radon diffusion as the probe of microstructure changes in solids, J. Therm. Anal. Calorim., 67, 49-61.

Beirau, T., Mihailova, B., Matveeva, G., Kolb, U., Malcherek, T., Groat, L.A. \& Bismayer, U., 2012. Structural anisotropy and annealing-induced nanoscale atomic rearrangements in metamict titanite, Am. Mineral., 97, $1354-1365$.

Beirau, T., Nix, W.D., Ewing, R.C., Schneider, G.A., Groat, L.A. \& Bismayer, U., 2016. Mechanical properties of natural radiation-damaged titanite and temperature-induced structural reorganization: a nanoindentation and Raman spectroscopic study, Am. Mineral., 101, 399-406.

Benavente, D., Canaveras, J.C., Cuezva, S., Laiz, L. \& Sanchez-Moral, S., 2009. Experimental definition of microclimatic conditions based on water transfer and porous media properties for the conservation of prehistoric constructions: Cueva Pintada at Galdar, Gran Canaria, Spain, Environ. Geol., 56, 1495-1504.

Bikit, I., Mrdja, D., Bikit, K., Grujic, S., Knezevic, D., Forkapic, S. \& Kozmidis-Luburic, U., 2015. Radon adsorption by zeolite, Radiat. Meas., 72, 70-74.

Blundy, J., Cashman, K. \& Humphreys, M., 2006. Magma heating by decompression-driven crystallization beneath andesite volcanoes, Nature, 443, 76-80.

Bonaccorso, A., Currenti, G., Del Negro, C. \& Boschi, E., 2010. Dike deflection modelling for inferring magma pressure and withdrawal, with application to Etna 2001 case, Earth planet. Sci. Lett., 293, 121-129.

Brindley, G.W., Sharp, J.H., Patterson, J.H. \& Narahari, B N., 1967. Kinetics and mechanism of dehydroxylation processes. I. Temperature and vapor pressure dependence of dehydroxylation of kaolinite, Am. Mineral., 52, 201-211.

Cicerone, R.D., Ebel, J.E. \& Britton, J., 2009. A systematic compilation of earthquake precursors, Tectonophysics, 476, 371-396.

Coppola, D. et al., 2017. Shallow system rejuvenation and magma discharge trends at Piton de la Fournaise volcano (La Réunion Island), Earth planet. Sci. Lett., 463, 13-24.

De Simone, G., Lucchetti, C., Galli, G. \& Tuccimei, P., 2016. Correcting for $\mathrm{H}_{2} \mathrm{O}$ interference using electrostatic collection-based silicon detectors, J. Environ. Radioact., 162-163, 146-153.

Etiope, G. \& Martinelli, G., 2002. Migration of carrier and trace gases in the geosphere: an overview, Phys. Earth planet. Inter., 129, 185-204.

Fernandez-Cortes, A., Benavente, D., Cuezva, S., Canaveras, J.C., AlvarezGallego, M., Garcia-Anton, E., Soler, V. \& Sanchez-Moral, S., 2013. Effect of water vapour condensation on the radon content in subsurface air in a hypogeal inactive-volcanic environment in Galdar cave, Spain, Atmos. Environ., 75, 15-23.

Fialips, C.I., Carey, J.W., Vaniman, D.T., Bish, D.L., Feldman, W.C. \& Mellon, M.T., 2005. Hydration state of zeolites, clays, and hydrated salts under present-day martian surface conditions: can hydrous minerals account for Mars Odyssey observations of near-equatorial water-equivalent hydrogen?, Icarus, 178, 74-83.

Finizola, A. et al., 2010. Adventive hydrothermal circulation on Stromboli volcano (Aeolian Islands, Italy) revealed by geophysical and geochemical approaches: implications for general fluid flow models on volcanoes, $J$. Volc. Geotherm. Res., 196, 111-119.

Flugge, S. \& Zimens, K.E., 1939. Die Bestimmung von Korngrossen und von Diffusionkonstanten aus dem Emaniervermogen, Z. Phys. Chem., 42, 179-220.

Frisch, M.A. \& Giess, E.A., 1990. Thermal Desorption Kinetics of Water from Glass Powders Studied by Knudsen Effusion Mass Spectroscopy, Materials Chemistry at High Temperatures: Characterization, ed. Hastie, J.W., pp. 175-185, Humana Press.

Gervino, G., Cigolini, C., Lavagno, A., Marino, C., Prati, P., Pruiti, L. \& Zangari, G., 2004. Modelling temperature distributions and radon emission at Stromboli Volcano using a non-extensive statistical approach, Phys. A, 340, 402-409.

Giammanco, S., Sims, K.W.W. \& Neri, M., 2007. Measurements of ${ }^{220}$ Rn and ${ }^{222} \mathrm{Rn}$ and $\mathrm{CO}_{2}$ emissions in soil and fumarole gases on Mt. Etna volcano (Italy): implications for gas transport and shallow ground fracture, Geochem. Geophys. Geosyst., 8, Q10001, doi:10.1029/2007GC001644.

Giampaolo, C., Mengarelli, L., Torracca, E. \& Spencer, C., 2008. Zeolite characterization of "Vico red tuff with black scoria" ignimbrite flow: the extractive district of Civita Castellana (Viterbo, Italy), Il Nuovo Cimento $B, \mathbf{1 2 3}, 1459-1476$.

Giordano, D., Russell, J.K. \& Dingwell, D.B., 2008. Viscosity of magmatic liquids: a model, Earth planet. Sci. Lett., 271, 123-134.

Glasstone, S., Laidler, K.J. \& Eyring, H., 1941. The Theory of Rate Processes: The Kinetics of Chemical Reactions, Viscosity, Diffusion and Electrochemical Phenomena, p. 611, McGraw-Hill, New York. 
Hartmann, J. \& Levy, J.K., 2005. Hydrogeological and gasgeochemical earthquake precursors - a review for application, Nat. Hazards, 34, 279 304.

Hauksson, E., 1981. Radon content of groundwater as an earthquake precursor: evaluation of worldwide data and physical basis, J. geophys. Res., 86(B10), 9397-9410.

Heap, M.J., Mollo, S., Vinciguerra, S., Lavallée, Y., Hess, K.-U., Dingwell, D.B., Baud, P. \& Iezzi, G., 2013. Thermal weakening of the carbonate basement under Mt. Etna volcano (Italy): implications for volcano instability, J. Volc. Geotherm. Res., 250, 42-60.

Heiligmann, M., Stix, J., Williams-Jones, G., Sherwood Lollar, B. \& Garzon, G., 1997. Distal degassing of Radon and Carbon Dioxide on Galeras volcano, Colombia, J. Volc. Geotherm. Res., 77, 267-283.

Holub, R.F. \& Brady, B.T., 1981. The effect of stress on radon emanation from rock, J. geophys. Res., 86, 1776-1784.

Kerr, R.A., 1978. Earthquakes: prediction proving elusive, Science, 200, 419-421.

King, C.-Y., 1981. Do radon anomalies predict earthquakes?, Nature, 293(5830), 262, doi:10.1038/293262a0.

Koike, K., Yoshinaga, T., Suetsugu, K., Kashiwaya, K. \& Asaue, H., 2015. Controls on radon emission from granite as evidenced by compression testing to failure, Geophys. J. Int., 203, 428-436.

Kotsarenko, A., Yutsis, V., Grimalsky, V. \& Koshevaya, S., 2016. Detailed study of radon spatial anomaly in tlamacas mountain area, volcano popocatepetl, Mexico, Open J. Geol., 6, 158-164.

Lange, R.A. \& Carmichael, I.S.E., 1987. Densities of $\mathrm{Na}_{2} \mathrm{O}-\mathrm{K}_{2} \mathrm{O}-\mathrm{CaO}-$ $\mathrm{MgO}-\mathrm{FeO}-\mathrm{Fe}_{2} \mathrm{O}_{3}-\mathrm{Al}_{2} \mathrm{O}_{3}-\mathrm{TiO}_{2}-\mathrm{SiO}_{2}$, liquids: new measurements and derived partial molar properties, Geochim. Cosmochim. Acta., 53, 21952204.

La Delfa, S., Vizzini, F. \& Patanè, G., 2012. Radon migration into different building types at medium and low south-eastern flank of Mt Etna (Sicily): connection with the volcanic activity, Environ. Earth Sci., 66, 923-931.

Martinelli, G. \& Dadomo, A., 2017. Factors constraining the geographic distribution of earthquake geochemical and fluid-related precursors, Chem. Geol., in press, doi:10.1016/j.chemgeo.2017.01.006.

Megumi, K. \& Mamuro, T., 1973. Radon and thoron exhalation from the ground, J. geophys. Res., 78(11), 1804-1808.

Megumi, K. \& Mamuro, T., 1974. Emanation and exhalation of radon and thoron gases from soil particles, J. geophys. Res., 79, 3357-3360.

Merle, O., Barde-Cabusson, S. \& vanWyk de Vries, B., 2010. Hydrothermal calderas, Bull. Volcanol., 72, 131-147.

Mollo, S., Tuccimei, P., Heap, M.J., Vinciguerra, S., Soligo, M., Castelluccio, M., Scarlato, P. \& Dingwell, D.B., 2011. Increase in radon emission due to rock failure: an experimental study, Geophys. Res. Lett., 38, L14304, doi:10.1029/2011GL047962.

Mollo, S., Misiti, V., Scarlato, P. \& Soligo, M., 2012. The role of cooling rate in the origin of high temperature phases at the chilled margin of magmatic intrusions, Chem. Geol., 322-323, 28-46.

Mollo, S., Giacomoni, P.P., Coltorti, M., Ferlito, C., Iezzi, G. \& Scarlato, P., 2015. Reconstruction of magmatic variables governing recent Etnean eruptions: constraints from mineral chemistry and $\mathrm{P}-\mathrm{T}-\mathrm{fO}_{2}-\mathrm{H}_{2} \mathrm{O}$ modelling, Lithos, 212-215, 311-320.

Mordret, A., Jolly, A.D., Duputel, Z. \& Fournier, N., 2010. Monitoring of phreatic eruptions using interferometry on retrieved cross-correlation function from ambient seismic noise: results from Mt. Ruapehu, New Zealand, J. Volc. Geotherm. Res., 191, 46-59.

Neri, M., Behncke, B., Burton, M., Galli, G., Giammanco, S., Pecora, E., Privitera, E. \& Reitano, D., 2006. Continuous soil radon monitoring during the July 2006 Etna eruption, Geophys. Res. Lett., 33, L24316, doi:10.1029/2006GL028394.

Neri, M., Ferrera, E., Giammanco, S., Currenti, G., Cirrincione, R., Patanè, G. \& Zanon, G., 2016. Soil radon measurements as a potential tracer of tectonic and volcanic activity, Sci. Rep., 6, doi:10.1038/srep24581.

Neuhoff, P.S. \& Wang, J., 2007. Isothermal measurement of heats of hydration in zeolites by simultaneous thermogravimetry and differential scanning calorimetry, Clay Clay Miner., 55, 239-252.
Nicolas, A., Girault, F., Schubnel, A., Pili, É., Passelegue, F., Fortin, J. \& Deldicque, D., 2014. Radon emanation from brittle fracturing in granites under upper crustal conditions, Geophys. Res. Lett., 41, 5436-5443.

Oppenheimer, C., 2003. Volcanic Degassing: Treatise on Geochemistry, Vol. 3, pp. 123-166, eds Rudnick, R.L., Holland, E.D. \& Turekian, K.K., Elsevier.

Palladino, D.M., Gaeta, M., Giaccio, B. \& Sottili, G., 2014. On the anatomy of magma chamber and caldera collapse: the example of trachyphonolitic explosive eruptions of the Roman Province (central Italy), J. Volc. Geotherm. Res., 281, 12-26.

Papachristodoulou, C., Ioannides, K. \& Spathis, S., 2007. The effect of moisture content on radon diffusion through soil: assessment in laboratory and field experiments, Health Phys., 92, 257-264.

Passaglia, E., Vezzalini, G. \& Carnevali, R., 1990. Diagenetic chabazites and phillipsites in Italy: crystal chemistry and genesis, Eur. J. Miner., 2, 827-839.

Prasad, G., Ishikawa, T., Hosoda, M., Sorimachi, A., Janik, M., Sahoo, S.K. \& Uchida, S., 2012. Estimation of radon diffusion coefficients in soil using an updated experimental system, Rev. Sci. Instrum., 83, 093503, doi:10.1063/1.4752221.

Ricci, T., Finizola, A., Barde-Cabusson, S., Delcher, E., Alparone, S., Gambino, S. \& Miluzzo, V., 2015. Hydrothermal fluid flow disruptions evidenced by subsurface changes in heat transfer modality: the La Fossa cone of Vulcano (Italy) case study, Geology, 43, 959-962.

Roca, V., De Felice, P., Esposito, A.M., Pugliese, M., Sabarrese, C. \& Vaupotich, J., 2004. The influence of environmental parameters in electrostatic cell radon monitor response, Appl. Radiat. Isot., 61, 243-247.

Roeloffs, E.A., 1988, Hydrologic precursors to earthquakes: a review, Pure appl. Geophysics, 126, 177-209.

Scarlato, P., Tuccimei, P., Mollo, S., Soligo, M. \& Castelluccio, M., 2013. Contrasting radon background levels in volcanic settings: clues from ${ }^{220} \mathrm{Rn}$ activity concentrations measured during long-term deformation experiments, Bull. Volcanol., 75, 751, doi:10.1007/s00445-013-0751-0.

Schubert, M. \& Paschke, A., 2015. Radon, $\mathrm{CO}_{2}$ and $\mathrm{CH}_{4}$ as environmental tracers in groundwater/surface water interaction studies - comparative theoretical evaluation of the gas specific water/air phase transfer kinetics, Eur. Phys. J. Spec. Top., 224, 709-715.

Shim, S.H., Navrotsky, A., Gaffney, T.R. \& MacDougall, J.E, 1999. Chabazite: energetics of hydration, enthalpy of formation, and effect of cations on stability, Am. Mineral., 84, 1870-1882.

Shuleikin, V. N., 2015. Water vapor, atmospheric electricity, and radon transfer to the near-surface soil layers and the atmosphere, Atmosp. Ocean. Phys., 51, 688-692.

Shweikani, R., Giaddui, T.G. \& Durrani, S.A., 1995. The effect of soil parameters on the radon concentration values in the environment, Radiat. Meas., 25, 581-584.

Shewmon, P.G., 1963. Diffusion in Solids, McGraw-Hill Book Co.

Simonot-Grange, M.H., 1979. Thermodynamic and structural features of water sorption in zeolites, Clays Clay Miner., 7, 423-428.

Steinitz, G., Begin, Z.B. \& Gazit-Yaari, N., 2003. Statistically significant relation between radon flux and weak earthquakes in the Dead Sea rift valley, Geology, 31, 505-508.

Tanner, A.B., 1978. Radon Migration in the Ground: A Supplementary Review, Open File Rep. 78-1050, U.S. Geological Survey.

Thomas, D., 1988. Geochemical precursors to seismic activity, Pure appl. Geophys., 126, 241-266.

Toutain, J.P. \& Baubron, J.C., 1999. Gas geochemistry and seismotectonics: a review, Tectonophysics, 304, 1-27.

Tomozawa, M., 1985. Concentration dependence of the diffusion coefficient of water in $\mathrm{SiO}_{2}$ Glass, J. Am. Ceram. Soc., 68, C-251-C-252.

Tsunogai, U. \& Wakita, H., 1995. Precursory chemical changes in ground water: Kobe earthquake, Japan, Science, 269, 61-63.

Tuccimei, P., Castelluccio, M., Soligo, M. \& Moroni, M., 2009. Radon Exhalation Rates of Building Materials: Experimental, Analytical Protocol and Classification Criteria, Building Materials: Properties, Performance and Applications, pp. 259-273, eds Cornejo, D.N. \& Haro, J.L., Nova Sci., Hauppauge, New York. 
Tuccimei, P., Mollo, S., Vinciguerra, S., Castelluccio, M. \& Soligo, M., 2010. Radon and thoron emission from lithophysae-rich tuff under increasing deformation: an experimental study, Geophys. Res. Lett., 37, L05305, doi:10.1029/2009GL042134

Tuccimei, P., Castelluccio, M., Moretti, S., Mollo, S., Vinciguerra, S. \& Scarlato, P., 2011. Thermal enhancement of Radon emission from geological materials, in Implications for Laboratory Experiments on Rocks Under Increasing Deformation: Horizons in Earth Science Research, Vol. 4, pp. 247-256, eds Veress, B. \& Szigethy, J., Nova Science Publishers, New York.

Tuccimei, P., Mollo, S., Soligo, M., Scarlato, P. \& Castelluccio, M., 2015. Real-time setup to record radon emission during rock deformation: implications for geochemical surveillance, Geosci. Instrum. Methods Data Syst., 4, 111-119.

Vetere, F. et al., 2015. Glass forming ability and crystallization behaviour of sub-alkaline silicate melts, Earth Sci. Rev., 150, 25-44.

Voltaggio, A., Masi, U., Spadoni, M. \& Zampetti, G., 2006. A methodology for assessing the maximum expected radon flux from soils in Northern Latium (Central Italy), Environ. Geochem. Health, 28, 541-551.

Whittington, A.G., Hofmeister, A.M. \& Nabelek, P.I., 2009. Temperaturedependent thermal diffusivity of the Earth's crust and implications for magmatism, Nature, 458, 319-321.

Woith, H., 2015. Radon earthquake precursor: a short review, Eur. Phys. J. Spec. Top., 224, 611-627.

Wohletz, K.H., Orsi, G. \& Civetta, L., 1999. Thermal evolution of the Phlegraean magmatic system, J. Volc. Geotherm. Res., 91, 381-414.

Zhang, W., Zhang, D., Wu, L., Li, J. \& Cheng, J., 2016. Radon release from underground strata to the surface and uniaxial compressive test of rock samples, Acta Geodyn. Geomater, 13, 407-416.

Zhuravlev, L.T., 2000. The surface chemistry of amorphous silica, Zhuravlev model, Colloids Surf. A-Physicochem. Eng. Asp., 173, 1-38.

\section{SUPPORTING INFORMATION}

Supplementary data are available at $G J I$ online.

Figure S1. (a) Photomicrograph of the cylindrical rock sample used for the experiments. (b) Photomicrograph of the cineritic matrix and centimetre-sized vesicles from an optical microscope using reflected light. (c) Backscattered electron (BSE) image showing clinopyroxene and feldspar of magmatic origin. (d) BSE image showing the zeolitization process of the cineritic matrix. (e) BSE image showing tabular and elongated clay minerals in the rock matrix. (f) BSE image of Sample1 showing the amorphous glass that is produced by heating the system up to $800{ }^{\circ} \mathrm{C}$ (EXP1). (g) BSE image of Sample1 showing the devolatilization of chabazite resulting from the dehydration process at $800{ }^{\circ} \mathrm{C}$ (EXP1).

Table S1. Microprobe analyses of minerals and glasses. $\mathrm{H}_{2} \mathrm{O}$ has been calculated by the 'difference from 100' method (i.e. based on the difference to $100 \%$ of the total obtained by EMP analyses, with accuracy of $c a .0 .5 \mathrm{wt} . \% \mathrm{H}_{2} \mathrm{O}$ ).

Table S2. Thermogravimetric (TG), differential thermogravimetric (DTG) and differential scanning calorimetric (DSC).

Table S3. X-ray powder diffraction (XRPD) data.

Table S4. Le Bail and Rietveld refinements of X-ray powder diffraction (XRPD) data.

Please note: Oxford University Press is not responsible for the content or functionality of any supporting materials supplied by the authors. Any queries (other than missing material) should be directed to the corresponding author for the paper. 